\title{
Faces as releasers of contagious yawning: An approach to face detection using normal human subjects
}

\author{
ROBERT R. PROVINE \\ University of Maryland Baltimore County, Baltimore, Maryland
}

\begin{abstract}
The yawn-evoking potency of variations in a 5-min series of 30 videotaped repetitions of a yawning face were compared with each other and with a series of 30 videotaped smiles to determine the ethological releasing stimulus for the fixed-action pattern of yawning and to understand the more general process of face detection. Animate video images of yawning faces in several axial orientations evoked yawns in more subjects than did featureless or smiling faces, and no single feature, such as a gaping mouth, was necessary to evoke yawns. The yawn recognition mechanism is neither axially specific nor triggered by an isolated facial feature.
\end{abstract}

The contagiousness of yawning is legendary. Viewing, reading about, and thinking about yawning evokes yawns (Provine, 1986). Although yawning is interesting in its own right (Provine, 1986; Provine \& Hamernik, 1986; Provine, Hamernik, \& Curchack, 1987; Provine, Tate, $\&$ Geldmacher, 1987), the present study uses the contagiousness of yawns as a means of assaying the yawnevoking potency of various facial features. The search for the ethological releasing stimulus that triggers the fixedaction pattern of yawning (Provine, 1986) also provides insights into the more general problem of face detection. The discovery of a perceptual process activated exclusively by visually observed yawns (Provine, 1986, 1989) establishes a precedent for a facial-feature and/or expression detector in humans. Similar detectors may exist for facial expressions other than yawns and for other complex visual stimuli, but their activity may be more difficult to monitor because they lack a contagious response as a behavioral assay. The study of contagious yawning provides a simple, noninvasive, behavioral approach to the neural basis of face perception that complements neuropsychological (Meadows, 1974; Whiteley \& Warrington, 1977) and neurophysiological analyses (Bruce, Desimone, \& Gross, 1981; Kendrick \& Baldwin, 1987; Perrett, Mistlin, \& Chitty, 1987; Perrett, Rolls, \& Caan, 1982).

\section{METHOD}

\section{Subjects}

Twelve experimental groups were each composed of 10 male and 20 female volunteers from introductory psychology classes; this female-

The author acknowledges the assistance of Kimberly Provine and David Nodonly in collecting data, and the editorial comments of Marilyn Demorest. Portions of this paper were reported at the annual meeting of the Society for Neuroscience, Toronto, Ontario, Canada in November 1988. Requests for reprints should be sent to Robert R. Provine, Department of Psychology, University of Maryland Baltimore County, Baltimore, MD 21228. to-male ratio reflected the greater representation of females in the subject pool. The 360 subjects had an average age of 19.7 years (range 18-54 years). Each subject participated in a single experimental session that occurred between 12:30 p.m. and 5:30 p.m.

\section{Procedure}

The yawn-evoking potency of variations in a 5-min series of 30 repetitions of a yawning face were compared with each other and with a series of 30 smiles. Single video frames of the stimuli in mid-yawn or mid-smile are shown in Figure 1. A video editing console in the university television studio was used to modify the videotaped yawn stimuli first used in an earlier study (Provine, 1986). Deleted areas of the face were filled in with a neutral shade that matched the intact surround. The borders of the deleted areas were diffused to reduce their visibility. A monochrome monitor was used to present stimuli in order to avoid the color shifts that occur when a color monitor is rotated. The stimuli were presented on a $29.9-\mathrm{cm}$-square video screen $1.5 \mathrm{~m}$ distant from the individually tested subjects. The subjects were instructed via a video monitor to observe the monitor and to record their yawns, if any should occur, by pressing a button (Provine, 1986). The button activated an event recorder that registered the temporal distribution of their yawns. Subjects were not otherwise observed, in order to avoid possible social inhibition of yawning.

\section{RESULTS}

The normal yawning face (Figure 1a) was an effective yawn-evoking stimulus. The 5-min series of 30 repetitions of a normal, animate yawn stimulated 16 subjects (Figure $2,0^{\circ}$, upper graph) to yawn 92 times (Figure 2, $0^{\circ}$, lower graph). In contrast, only 7 subjects emitted a total of 16 yawns in response to a 5-min series of smiles (Figures $1 \mathrm{~h}$ and 2). A two-tailed chi-square test determined this difference in number of yawners to be statistically significant $\left[\chi^{2}(1, N=60)=5.71, p<.02\right]$. (Subsequent tests of the significance of difference between the frequencies of yawning subjects used this chi-square test. The total yawns evoked per condition are reported without statistical test because of the variability in the number of yawning subjects in different conditions.)

The yawn-detection process was not axially selective. Yawns in orientations of $90^{\circ}, 180^{\circ}$, and $270^{\circ}$ were as 


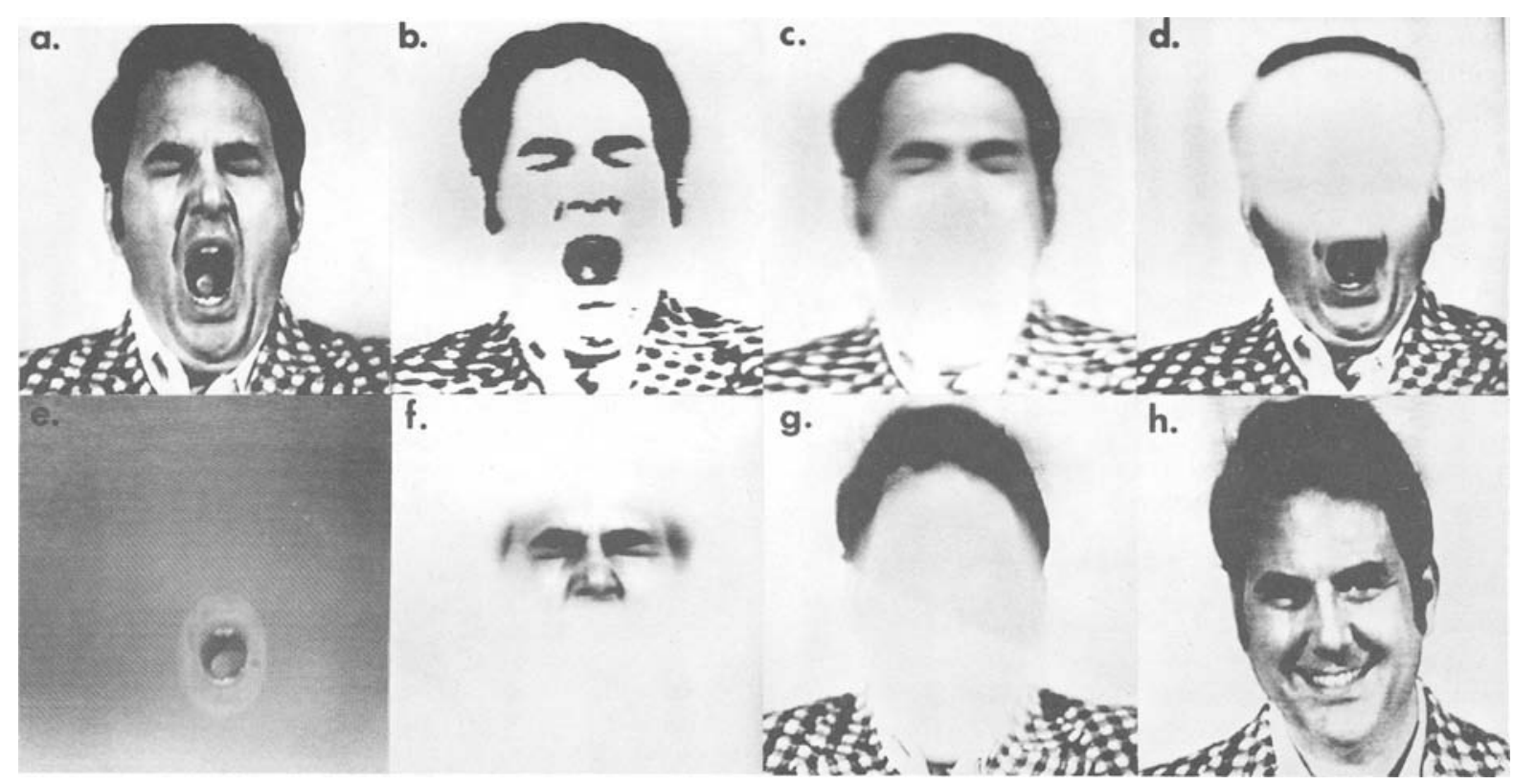

Figure 1. Single frames of video stimuli in mid-yawn or mid-smile. All stimuli were animate except for the single tonic (still) condition resembling (a). (a) Normal halftone yawn; (b) high-contrast yawn; (c) no-mouth yawn; (d) no-eyes yawn; (e) mouth-only yawn; (f) eyesonly yawn; (g) no-face yawn; (h) smile.

potent or nearly as potent in evoking yawns as was the normal, upright $0^{\circ}$ yawn (Figure 2 ). Significantly more subjects yawned in response to $0^{\circ}\left[\chi^{2}(1, N=60)=5.71\right.$, $p<.02], 90^{\circ}\left[\chi^{2}(1, N=60)=5.71, p<.02\right]$, and $180^{\circ}$ $\left[\chi^{2}(1, N=60)=7.05, p<.01\right]$ yawns than to the smile

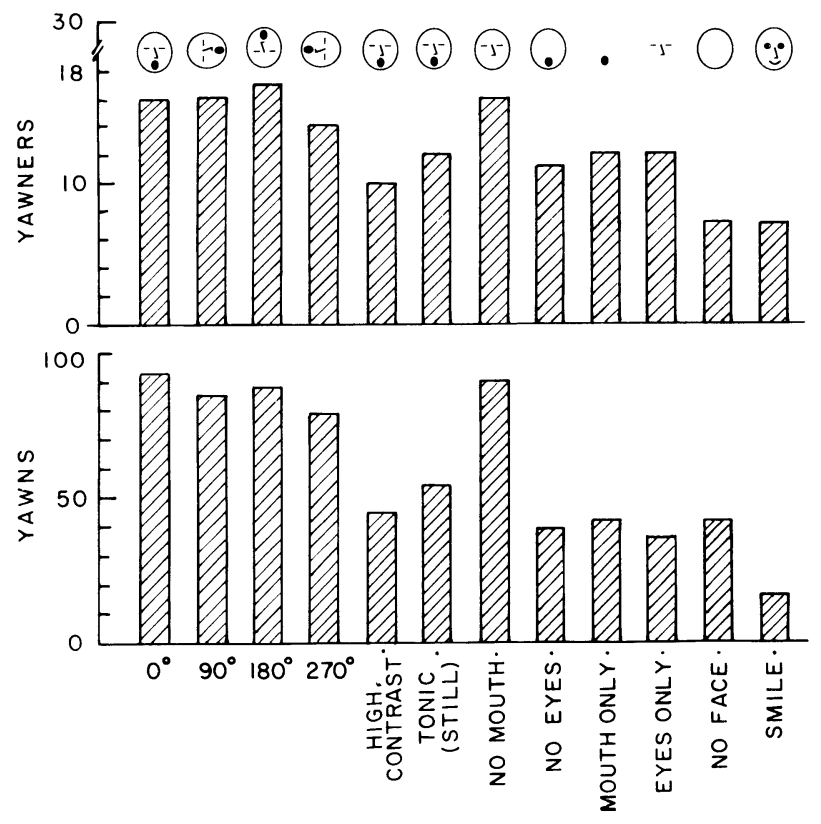

Figure 2. The number of subjects who yawned (upper graph) and the total yawns (lower graph) evoked by various yawn and smile stimuli. The stimuli are shown in cartoon form at the top of the figure and labeled at the bottom of the figure. Independent groups of 30 subjects participated in each of the 12 stimulus conditions. stimulus; the results of the test that compared the $270^{\circ}$ yawn and the smile stimuli approached significance $\left[\chi^{2}(1\right.$, $N=60)=3.59, p<.10]$.

The number of subjects who yawned in response to the high-contrast yawn (Figure 1b) did not differ significantly from those who yawned in response to either the normal halftone yawn $\left[\chi^{2}(1, N=60)=2.44, p<.2\right]$ or the smile stimulus $\left[\chi^{2}(1, N=60)=.74, p<.5\right]$. Although the high-contrast yawn had much of the edge and contour information that distinguishes the yawning face, the novelty of the image may have distracted some subjects. One participant commented that he was tempted to yawn but did not because the stimulus looked "strange."

A tonic (still) mid-yawn video frame (Figure 1a) produced a number of yawners midway between, and not significantly different from, that produced by normal, animate yawns $\left[\chi^{2}(1, N=60)=1.07, p<.3\right]$ or smiles $\left[\chi^{2}(1, N=60)=1.93, p<.2\right]$ (Figure 2).

The "no-mouth" yawn (Figure 1c) was the only stimulus with a deleted feature that produced as many yawning subjects as did the complete face and significantly more yawning subjects than did the smile $\left[\chi^{2}(1, N=60)\right.$ $=5.71, p<.02]$ (Figure 2). Thus, a gaping mouth, one of the most striking features of a yawning face, was not essential to evoke high rates of yawning. The spontaneous comments of two subjects may partially explain this result; both said that there was an illusion of a yawning mouth in the featureless blank area normally occupied by the mouth. The unexpected effectiveness of the no-mouth stimulus was complemented by the finding that the "'mouth-only" yawn (Figure 1e) was a relatively ineffective yawn-evoking stimulus (Figure 2). The number of 
yawners produced by the mouth-only stimulus was not significantly different from that of either normal yawns $\left[\chi^{2}(1, N=60)=1.07, p<.3\right]$ or smiles $\left[\chi^{2}(1, N=60)\right.$ $=1.93, p<.2]$.

The "no-eyes" yawn (Figure 1d) produced few yawners and yawns, but the number of yawners was not significantly different from that of either the normal yawn $\left[\chi^{2}(1, N=60)=1.68, p<.2\right]$ or the smile stimuli $\left[\chi^{2}(1\right.$, $N=60)=1.27, p<.3$ ] (Figure 2). The "eyes-only" yawn, in which the eyes were presented alone out of their normal facial context (Figure 1f), also produced an intermediate number of yawners (Figure 2), which did not differ significantly from that of normal yawns $\left[\chi^{2}(1\right.$, $N=60)=1.07, p<.3]$ or smiles $\left[\chi^{2}(1, N=60)=1.93\right.$, $p<.2]$. The eyes-only and the mouth-only stimuli were almost identical with regard to the number of yawning subjects and total yawns produced.

The "no-face" yawn (Figure 1g) produced no more yawning subjects and only a few more yawns than did smiles (Figure 2), and was the only modified yawn stimulus that produced significantly fewer yawners than did the normal yawn stimulus $\left[\chi^{2}(1, N=60)=5.71, p<.02\right]$. The only yawn-related cues of the no-face stimulus were tilting of the head and jaw movement, which cause changes in the perimeter and position of the face.

\section{DISCUSSION}

The ability of visually observed yawns to evoke yawning in witnesses was confirmed by the present research (also see Provine, 1986). Observers responded to the overall configuration of the yawning face independent of its axial orientation, and no single facial feature, such as a gaping mouth, served as a sign or releasing stimulus necessary to evoke yawning. A similar lack of feature and axial specificity in many facespecific neurons in the brains of monkeys suggests a related stimulus analysis (Bruce, Desimone, \& Gross, 1981; Perrett, Mistlin, \& Chitty, 1987; Perrett, Rolls, \& Caan, 1982). These results about contagious yawning and face-specific neurons support those in studies of prosopagnosia (face nonrecognition) in brain-damaged humans (Meadows, 1974; Whiteley \& Warrington, 1977), and perhaps even the results of studies of facial imitation in human neonates (Field, Woodson, Greenberg, \& Cohen, 1982; Meltzoff \& Moore, 1977; Provine, 1989), which suggest that special neural mechanisms detect and process information about faces. These diverse behavioral and neurophysiological results may be the product of a common underlying perceptual process; it seems unlikely that complex neural mechanisms for similar visual tasks would evolve independently and have radically different principles of operation.

Viewing a yawn triggers in us the urge to yawn, although we have no conscious desire to imitate the yawner. This extraordinary neurobehavioral phenomenon has been overlooked as a scientific problem because it is commonplace. Yet contagious yawning offers a useful tool for the exploration of a variety of phenomena, only some of which directly concern yawning. For example, the present search for the releaser of yawning has implications for a topic of more general concern, namely, sensory feature detection. At present, the data for contagious yawning may be the best evidence for an expression-specific visual-detection process in humans. The study of contagious yawning is also a good starting point for the investigation of contagion, a class of behavior that has been neglected by social psychologists.

The analysis of yawning may also provide insights into behavioral evolution. For example, is it fortuitous that the releasing stimulus for yawning is a view of the act of yawning, or does the motor act play some active role in the evolution of the visual mechanism specific for its detection? We know only that yawning is a phylogenetically ancient behavior performed by many, if not most, vertebrates, probably as a homeostatic response to yet unknown physiological states (Provine, Tate,
\& Geldmacher, 1987). Yawning may have evolved as the cephalic component of a generalized stretch response that became partially autonomous (Provine, Hamernik, \& Curchack, 1987). The finding that yawning is most common in uninteresting situations (Provine \& Hamernik, 1986), and shortly before bedtime and after waking (Provine, Hamernik, \& Curchack, 1987), suggests that it may have an arousing function. The high frequency of yawning in bored and drowsy people is probably the basis for yawning as a paralinguistic signal for these states (Provine \& Hamernik, 1986; Provine, Hamernik, \& Curchack, 1987). However, the question of an arousing function for yawning is still open; yawning might be arousing, dearousing, both, or neither, and the result might be specific to the situation and/or time of day. In fact, one important consequence of yawning, the opening of the eustachian tubes to balance middle ear pressure, has nothing to do with arousal (Laskiewicz, 1953). Yawning, like associated stretching, is a high-amplitude behavior that involves many body parts. Identifying one of the large family of likely physiological correlates of yawning as its principal function may be difficult, if not impossible. As with stretching, yawning may have several functions. However, the hunt for these functions has been narrowed by the rejection of one of the most popular pieces of folklore about yawning: human yawning is not a response to blood or brain levels of carbon dioxide or oxygen, and it does not appear to serve a principal respiratory function (Provine, Tate, \& Geldmacher, 1987).

The releasing mechanism for contagious yawning evolved long after the phylogenetically ancient motor-pattern generator for the yawning act. Contagious yawning has been demonstrated with certainty only in humans (Provine, 1986, 1989), in whom it may have evolved as a means of synchronizing the behavior of group members. If yawning produces a physiological transformation in the yawner, then the chain reaction of contagious yawning synchronizes the physiological as well as the behavioral state of the group. Additional insights about the phylogeny of contagious yawning are offered by the examination of its ontogeny. Although the act of yawning may occur as early as the 11 th week after conception (DeVries, Visser, \& Prechtl, 1982), and is performed by newborns, contagious yawning may not appear until the second year after birth (Piaget, 1951; Provine, 1989). This developmental sequence accords with the evolutionary scenario described above; phylogenetically, ancient structures and behaviors are generally considered to develop before more recently evolved ones. In a passing comment, $\mathrm{Pi}$ aget (1951) provided an additional incentive for studying the development of contagious yawning; its onset may signal the emergence of imitation and a change in the child's relationship with its environment. However, further incentives for studying contagious yawning may be unnecessary. Although the analysis of yawning is in its infancy, its future looks bright. Contagious yawning has much to teach us about central issues in behavioral neuroscience.

\section{REFERENCES}

Bruce, C., Desimone, R., \& Gross, C. G. (1981). Visual properties of neurons in a polysensory area in superior temporal sulcus of the macaque. Journal of Neurophysiology, 46, 369-384.

DeVries, J. I., Visser, G. H. A., \& Prechtl, H. F. R. (1982). The emergence of fetal behavior: 1. Qualitative aspects. Early Human Development, 7, 301-322.

Field, T. M., Woodson, R., Greenberg, R., \& CoHen, D. (1982). Discrimination and imitation of facial expressions by neonates. Science, 218, 179-181.

Kendrick, K. M., \& BALDWIN, B. A. (1987). Cells in temporal cortex of conscious sheep can respond preferentially to the sight of faces. Science, 236, 448-450.

LASKIEWICZ, A. (1953). Yawning in regard to the respiratory organs and the ear. Acta Otolaryngology, 43, 267-270.

Meadows, J. C. (1974). The anatomical basis of prosopagnosia. Journal of Neurological \& Neurosurgical Psychiatry, 37, 489-501.

Meltzoff, A. N., \& Moore, M. K. (1977). Imitation of facial and manual gestures by human neonates. Science, 198, 75-78.

Perrett, D. I., Mistlin, A. J., \& Chitty, A. J. (1987). Visual neurons responsive to faces. Trends in Neuroscience, 10, 358-364.

PerretT, D. I., Rolls, E. T., \& CAAN, W. (1982). Visual neurons responsive to faces in the monkey temporal cortex. Experimental Brain Research, 47, 329-342. 
Piaget, J. (1951). Play, dreams and imitation in childhood. New York: Norton.

Provine, R. R. (1986). Yawning as a stereotyped action pattern and releasing stimulus. Ethology, 72, 109-122.

Provine, R. R. (1989). Contagious yawning and infant imitation. Bulletin of the Psychonomic Society, 27, 125-126.

Provine, R. R., \& Hamernik, H. B. (1986). Yawning: Effects of stimulus interest. Bulletin of the Psychonomic Society, 24, 437-438.

Provine, R. R., Hamernick, H. B., \& CURChaCK, B. C. (1987). Yawning: Relation to sleeping and stretching in humans. Ethology, 76, 152-160.
Provine, R. R., Tate, B. C., \& Geldmacher, L. L. (1987). Yawning: No effect of $3-5 \% \mathrm{CO}_{2}, 100 \% \mathrm{O}_{2}$, and exercise. Behavioral \& Neural Biology, 48, 382-393.

Whiteley, A. M., \& Warrington, E. K. (1977). Prosopagnosia: A clinical, psychological, and anatomical study in three patients. Journal of Neurological \& Neurosurgical Psychiatry, 67, 394-430.

(Manuscript received November 14, 1988.) 